\title{
LA ACCIÓN POPULAR: AVANCES \\ Y RETROCESOS FRENTE A \\ LOS CONTRATOS ESTATALES \\ QUE VULNERAN DERECHOS \\ COLECTIVOS.
}

Abogado de la U. Surcolombiana. Integrante del Semillero de Investigación "Facta Nom Verba"

\author{
Mauricio José Álvarez Tafur \\ Diego Omar Perez Salas - Docente Tutor
}

\section{RESUMEN}

La Acción Popular' como mecanismo de origen constitucional, ha generado en el ordenamiento jurídico colombiano importantes decisiones derivadas en la búsqueda de garantías de los derechos colectivos previstos en la Ley 472 del 98 , conllevando importantes cambios al interior del derecho administrativo y en especial en lo que concierne a la procedencia de ésta acción constitucional frente a hechos derivados de los contratos del Estado que vulneran o amenazan derechos e intereses colectivos, como lo es la moralidad administrativa ${ }^{2}$ y el patrimonio público.

\section{ABSTRACT}

The Popular Action as mechanism of constitutional origin, it has generated in the classification juridical Colombian important decisions derived in the search of guarantees of the collective rights foreseen in the Law 472 of the 98 , bearing important changes to the interior of the administrative right and especially concerning the origin of this constitutional action in front of derived facts of the contracts of the State that harm or they threaten rights and collective interests, as it is it the administrative morality and the public patrimony.

\footnotetext{
${ }^{1} \mathrm{La}$ administración, quien es la ejecutora por excelencia en la consecución de los fines del Estado, en ocasiones origina situaciones desfavorables a los administrados en lo relacionado con sus garantías, no cumpliendo fielmente sus deberes. Por tanto, el juez en última instancia se encarga de armonizar las situaciones que hayan generado conflicto, por vía de la participación de los ciudadanos que optan en la acción popular como medio constitucional para la protección de los derechos colectivos.

2 Aunque el derecho o interés colectivo a la moralidad administrativa no se encuentra definido en la Ley 472 de 1998 podemos precisar la siguiente definición: "Se entenderá por moralidad, administrativa el derecho que tiene la comunidad a que el patrimonio público sea manejado de acuerdo a la legislación vigente, con la diligencia y cuidados propios de un buen funcionario" (Cfr. Gaceta del Congreso No. 277 de septiembre 5 de 1995, pág. 1)
} 


\section{PALABRAS CLAVES}

Acción popular - moralidad administrativa - actividad contractual - derechos colectivos vulneración - patrimonio público.

\section{KEYWORDS}

Popular action - administrative morality - contractual activity - collective rights - public patrimony.

\section{LA ACCION POPULAR FRENTE A LOS CONTRATOS ESTATALES}

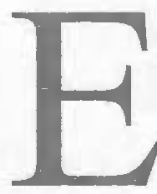

n el desarrollo de la investigación: “La Acción popular frente a los contratos estatales que vulneran o amenazan intereses y derechos colectivos", se avanza alrededor de las inquietudes que han surgido entorno al desarrollo jurisprudencial de la acción popular, ya que encierra la protección de los derechos e intereses colectivos del orden constitucional. Derechos que han resultado ser los que mayor dinámica dan al ejercicio de ésta acción cuando sể está frente a un contrato de la administración, que se celebra o ejecuta de manera irregular, situación que ha permitido que la acción popular despliegue la posibilidad de ejercer en cabeza de la sociedad un mayor control social, pues la ciudadanía se está involucrando con el interés público e interviene en la consecución de una congruencia entre los contratos de la administración y los derechos y garantías de los administrados.
Es así, que en el desarrollo de la investigación hemos presenciado que el ejercicio de la acción popular ha otorgado a la ciudadanía, un cierto poder social para exigir del Estado, de los individuos y del sector privado, (contratistas en el caso de la investigación,) el cumplimiento de ciertos principios y el respeto de situaciones jurídicas que benefician a la colectividad.

Las garantías que se buscan a través de la Acción Popular en el caso estudiado, se trasladan a lograr decisiones que lleguen a la protección efectiva de la moralidad administrativa y el patrimonio público ${ }^{3}$ cuando se está frente a situaciones que resultan perjudiciales a estos derechos, resultado de la inobservancia en materia contractual por parte de la administración, de criterios legales obligatorios y apreciaciones de conveniencia y oportunidad evidentes, así como por la omisión de la administración en lo atinente a la planificación administrativa y urbana de los proyectos ${ }^{3}$, que además en materia presupuestal han presentado situaciones irregulares frente al manejo inadecuado de los recursos públicos en donde se toma dinero de

\footnotetext{
${ }^{3}$ Es preciso señalar que el contenido de la moralidad administrativa y el patrimonio público es correlativo a la dinámica política y judicial que difícilmente pueden predefinirse en abstracto, pues dejan abierto un espacio amplio a la regulación legislativa, a las decisiones políticas y administrativas, propias de una sociedad democrática. Precisamente por ello, la dificultad en la hermenéutica de estos conceptos es indudable, puesto que en algunas ocasiones no es clara ni precisa la frontera entre su significado jurídico y su contenido político. Sentencia de la Sección Quinta del 24 de agosto de 2001, AP-100.
} 
otros rubros destinados a sectores que deberían privilegiarse, desconociendo de tal manera, el plan de inversiones propio del ente bajo controversia, así como los sobrecostos en la ejecución del contrato.

La búsqueda de la protección se materializa en el examen de legalidad de dicho contrato, luego de identificar que existe una amenaza o vulnëración a algún derecho colectivo, profiriéndose sentencias que han llegado a declarar la nulidad, suspensión provisional, revisión o modificaciones al interior de los contratos de la administración pública; decisiones que no han sido aceptadas por los contratistas, como a las entidades administrativas que suelen ser permisivas de las dinámicas de corrupción presentes en el desarrollo de los procesos administrativos concomitantes con la contratación pública. Esta situación ha desencadenado toda una serie de resistencias que tienen origen al interior de los intereses que promueve la contracultura de la corrupción administrativa, a la que obedece en una gran mayoría los sujetos que intervienen en la contratación estatal. Es por tal motivo que este tipo de cóntratación en Colombia se enfrenta hoy a una acción que entra a corregir desde su celebración, hasta su ejecución irregular, actividad que puede, bajo ciertas características según subreglas establecidas por la jurisprudencia contenciosa administrativa, perjudicar primordialmente la vigencia de la moralidad administrativa y del patrimonio público. $^{5}$
En el momento de dar aplicación a la moralidad administrativa como al patrimonio público, el Consejo de Estado esbozó una solución para privilegiar la eficacia de los principios constitucionales, sin lesionar la seguridad jurídica. Se dijo que los principios necesitan concreción por su textura abierta y se admitió la metodología de la concreción a través de ejemplos ${ }^{6}$, de manera que, cuando se produce tiene la capacidad de obrar respecto del principio, como elemento que lo hace reaccionar con un alcance determinado, llegando a la conclusión de afirmar la posición según la cual las normas de principio suponen un vacío jurídico, pues ellas sólo contienen aspiraciones ético - políticas y en esa medida, su aplicación contaminaría las verdaderas normas y alimentaría la desconfianza en el derecho. ${ }^{7}$

Las resistencias contra la consolidación de la Acción Popular como herramienta potencial en la configuración de una contratación estatal congruente y respetuosa del interés general, se han promovido principalmente por parte de tratadistas reconocidos como lo son Javier Tamayo Jaramillo y Sandra Morelli Rico, quienes han estado en la defensa de importantes gremios económicos, (construcción, servicios privados de telefonía, transporte de carga, comité de cafeteros, entre otros.) en el que los intereses de la rentabilidad de la contratación pública en ocasiones, escapan al alcance de proteger intereses de la colectividad. Estos tratadistas han ambientado el escenario

\footnotetext{
${ }^{4}$ Como es el caso del estadio de fútbol de Pasto, en donde la ubicación de la obra se desarrolló en una zona cuyas características eran inapropiadas. Consejo de Estado Sección Tercera. AP.-170 del 16 de febrero del 2001, M.P Ariel Eduardo Henríquez.

5 "Mientras no exista norma expresa que defina el contenido jurídico de los conceptos de moralidad y de defensa del patrimonio público, en cada caso corresponderá determinarlo al juez, quien debe efectuar un estudio de validez constitucional y legal de la opción políticamente escogida, por lo que podría decirse que el juez asume un control de límites normativos que condicionan al derecho la decisión discrecional, no arbitraria, de los órganos políticos. Sólo si se diferencian esas dos esferas, las funciones judicial y administrativa asumen su verdadero papel en el Estado Social de Derecho que se caracteriza por la separación y colaboración armónica entre las ramas y órganos del poder público". Sentencia de la Sección Quinta del 24 de agosto de 2001, AP-100.

${ }^{6}$ En lo que corresponde a esta metodología, el Consejo de Estado se ha remitido a los juristas Karl Larenz en su obra. Derecho Jnsto, fundamentos de ética jurídica Madrid: Editorial Civitas 1985 y Eduardo García de Enterría en su obra, Reflexiones sobre la Ley y los principios generales del Derecho. Madreid: Editorial Civitas. 1985.

Consejo de Estado Sección Tercera. AP.-170 del 16 de febrero del 2001, M.P Ariel Eduardo Henríquez
}

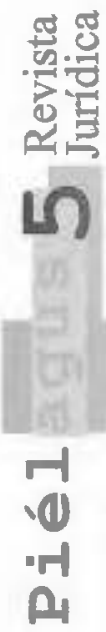


jurisprudencial y doctrinal con argumentos como los siguientes: "Los contratos estatales no se pueden aniquilar con base en una acción popular y sólo acudiendo a las vías especiales consagradas especialmente en la ley, será posible destruir el contrato"?.

\section{"Las acciones populares no fueron} concebidas ni por el constituyente, ni por el legtstador, como una especie de acciones supralegales y supraconstitucionales, que tengan la capacidad de absorber el resto de las acciones jurídicas, previstas en el ordenamiento jurídico para anular o exigir el cumplimiento de los contratos de la administración".

Además, sostienen la tesis restrictiva que da fundamento a la no procedencia de la Acción Popular frente a los contratos del Estado bajo ninguna excepcionalidad; dichos argumentos se mueven bajo la égida de proteger la seguridad jurídica en la que deben desplazarsen los intereses económicos que persiguen los grandes contratistas privados que tienen asiento en el territorio colombiano; intereses que se verían perjudicados si se llegase a consolidar una acción como la pópular, donde cualquier tercero está legitimado a proceder en el ejercicio de ésta acción frente a un contrato donde intervenga el Estado como parte, y cuando la moralidad administrativa o el patrimonio público se vean perjudicados o amenazados en el despliegue de la actividad contractual.
Este temor fue evidente por parte de los industriales y empresarios durante las iniciativas legislativas que se presentaron y no prosperaron al momento de llegar a reglamentar la acción popular, teniendo que pasar siete años para que se expidiera la ley por parte del Congreso de la República, ante la oposición de estos gremios, y hubo que esperar un año más para que iniciase su vigencia el 5 de agosto de 1999.

\section{UNA APROXIMACIÓN HACIA AVANCES SIGNIFICATIVOS.}

La Acción Popular ha dejado en su corto recorrido, grandes hitos respecto de situaciones que han sido objeto de su examen y juzgamiento tanto por Tribunales Administrativos como por las salas de decisión del Consejo de Estado, situaciones en las que ha estado inmerso el despliegue de la actividad contractual estatal o la manifestación de la voluntad del Estado bajo cualquier modalidad (acuerdo conciliatorio, convenio, Etc). ${ }^{10}$

Los casos en los que mayor protagonismo, tanto en medios como en ámbitos jurídicos ha logrado la Acción Popular, ha sido en los fallos frente al caso Invercolsa - Fernando Londoño, y el de Dragacol - Ministerio de Transporte, situaciones que exigieron una aplicación íntegra de la Ley 472 del 98, como también de los fallos expedidos por la Corte Constitucional ${ }^{11}$ $y$ de tesis de doctrinantes ${ }^{12}$ que promueven la procedencia de la Acción Popular, bajo ciertos $\operatorname{casos}^{13}$, frente a hechos derivados de los

${ }^{8}$ TAMAYO JARAMILLO, Javier. Las acciones populares y de grupo. Bogotá: Editorial Raisbeck, Lara, Rodríguez y Rueda (Baker \& McKenzie), Comentarios de Luis Felipe Botero Aristizabal. Pág.45

9 Ámbito jurídico. Año VII-No 161. Pág. 15

${ }^{10}$ En lo que respecta a la actividad contractual estatal, esta resulta cada vez más compleja de abordar por las cercanías que se han desarrollado entre el derecho privado y la contratación pública, situación que se presentó en la venta de acciones de Invercolsa, lo que después generaría la controversia entre Fernando Londoño Hoyos y ECOPETROL.

${ }_{11}^{11}$ C/088/2003. SU-047 de 1999, C-131 de 1993 y C-037 de 1996

${ }_{12}^{12}$ Como Luis Felipe Botero Aristizabal, Ricardo Hoyos Duque y Ariel Eduardo Henríquez.

13 "Que los contratos estatales pueden ser objeto de la acción popular, cuando a través de ellos se amenace o vulnere un derecho colectivo, así mismo que el juez puede examinar la legalidad o validez del contrato y si lo estima necesario para la protección de tales derechos, hacer cesar sus efectos o declarar su nulidad absoluta."... "La ley 472 de 1998 no señala expresamente que los contratos de la administración pública puedan ser objeto del examen de legalidad a través del ejercicio de la acción popular; sin embargo, el contrato es un instrumento para la inversión de los dineros públicos y como ésta acción busca la protección de derechos colectivos que pueden resultar afectados por las actuaciones de los servidores públicos, se impone concluir que por la vía de la acción popular puede ser posible revisar la legalidad de un contrato estatal cuando éste pone en peligro o viola algún derecho colectivo. Tesis sostenida por el Consejero de Estado Ricardo Hoyos Duque, durante las II Jornadas en Contratación Estatal. 
contratos del Estado, persiguiendo la búsqueda de protección de la moralidad administrativa y el patrimonio público de forma ejemplarizante ante hechos que evidenciaban un completo desarrollo irregular que transcendía en lo antijurídico e inmoral.

En el caso de Dragacol, el ejercicio de la Acción Popularseefectuó por iniciativa de la Contraloría General de la República, la cual perseguía que se suscribiera el acta de conciliación suscrita entre las partes (Ministerio de Transporte y Dragacol) el día 6 de noviembre de 1998, la cual en concepto de la Contraloría, carecía de efectos jurídicos por haberse constituido una vía de hecho y como consecuencia de lo ello, solicitaba que se restituyeran las cosas al estado anterior a la celebración de la conciliación.

La sentencia del Consejo de Estado ${ }^{14}$ generó efectos que repercutieron en el escenario nacional y especialmente en el de las relaciones Contratistas - Estado, desarrollándose medidas que rompieron la tradición que impera en el ordenamiento jurídico colombiano, sobre lo inocuo que resulta el sistema de mecanismos legales de corrección de la actividad Contractual Pública, cuando ésta se encuentra inmersa en situaciones de corrupción administrativa; considerando la Sala que "Aparecen otras circunstancias que no dejan duda sobre la imposibilidad legal del acuerdo conciliatorio y que permiten concluir que no se protegieron los intereses del Estado, porque - como se verá a continuación - se aceptaron como ciertas, una serie de pretensiones de la sociedad DRAGACOL, que no eran procedentes, con lo cual se violó la ley, en desmedro del patrimonio público."

Es así como la decisión, en búsqueda de una protección integral de los derechos colectivos de la moralidad administrativa y el patrimonio público declaró, sin efectos el acta del acuerdo conciliatorio de fecha 6 de noviembre de 1998, suscrita entre el Ministerio de Transporte y DRAGACOL S.A. ante el centro de conciliación de la Cámara de Comercio de Bogotá y como consecuencia de ello, el Ministerio de Transporte debió abstenerse de seguir ejecutando los pagos pendientes, e iniciar las acciones tendientes a la recuperación de las sumas que fueron canceladas.

Adicionalmente y teniendo en cuenta que ya se habían hecho efectivos los pagos por valor de diecisiete mil seiscientos millones de pesos (\$17.600.000.000.), originadosenlaçonciliación mencionada, seordenóala SociedaddeDragados y Construcciones de Colombia y del Caribe S. A. DRAGACOL S.A. a que devolviera en su totalidad al Ministerio de Transporte las sumas que resultaron pagadas en exceso; además declaró responsable solidario con la sociedad DRAGACOL S.A. al ex ministro de transporte Mauricio Cárdenas Santamaría, de conformidad con el inciso segundo del artículo 40 de la Ley 472 de 1998, por el valor no recuperado de lo pagado en exceso. La corrección consignada en el fallo referenciado, conllevó la defensa por parte de diferentes frentes (sociedad civil, Ongs, académicos del derecho, entre otros) sobre la necesidad de lograr un alcance de la Acción Popular, como instrumento que perfile la nulidad, suspensión o corrección de los actos de la administración (sean actos o contratos, etc) con una nueva perspectiva constitucional, dejando de ser meramente una sanción para proteger con exclusividad el bien jurídico de la legalidad formal, para convertirse junto con las acciones constitucionales y el mecanismo de inconstitucionalidad, en la herramienta con que cuenta el juez administrativo para dar cumplimiento concreto a la Constitución, dejando de ser sólo un ejercicio de subsunción abstracto de normas, a uno de valoración o

\footnotetext{
${ }^{14}$ Consejo de Estado, sección cuarta, Consejera ponente: LIGIA LOPEZ DIAZ (31) de mayo de dos mil dos (2002) Radicación número: 25000-23-24-000-1999-9001-01(AP-300)
} 
ponderación de las mismas a partir de los principios o valores y fines enmarcados en la Constitución, como en el caso del principioderecho de la moralidad administrativa, que en el sistema jurídico colombiano es a la vez un principiodelafunciónadministrativa consagrado en la misma Carta, artículo 209 así como en la Ley 498 del 98 artículo 3 y determinado además como derecho colectivo susceptible de protęcción por vía de la acción popular, construyéndose cada vez más argumentos que aportan razones sobre la legitimidad para proceder a revocar o anular todo contrato en donde intervengan recursos públicos en el que se presenten manejos inmorales o en los cuales se celebren bajo una forma deshonesta; situaciones que no son congruentes con una función pública que se deba mover bajo la orientación de una relación armoniosa entre la legalidad y la moralidad, ya que éstas en la actividad contractual administrativa no pueden marchar divorciadas.

\section{APROXIMACIÓN A LOS RETROCESQS EN LA ACCIÓN POPULÁR FRENTE A LAS GARANTÍAS CONSTITUCIONALES}

En el caso bajo referencia, se presentó posteriormente una variante trascendental que desmoronó por completo lo alcanzado por el fallo de Acción Popular proferido por el Consejo de Estado, ya que mediante sentencia SU- 881 de agosto de 2005, la Corte Constitucional halló una vía de hecho en el proceso adelantado, en lo que respecta a la solidaridad del exministro Mauricio Cárdenas Santamaría, con el exceso de lo pagado a Dragacol; vía de hecho que a criterio de la Corte, se configuró por la aplicación de la Ley 472 de 1998 a hechos ocurridos antes de la entrada en vigencia de la ley ya que ésta, no tenía aplicación retroactiva y además se había desconocido la ultractividad expresamente señalada por la ley; es así, como una vez declarada exequible por un fallo de constitucionalidad, anota la Corte Constitucional con argumentos categóricos: "En la presente sentencia se incurrió en una vía de hecho de carácter sustantivo, por la naturaleza de la norma que fue aplicada a pesar de ser manifiestamente inaplicable teniendo en cuenta los criterios de aplicación de la ley en el tiempo, lo cual implica, a su vez, el desconocimiento del principio de legalidad".

Ello conllevó a la Corte a definir, bajo la sentencia de unificación, un antecedente sobre este tipo de situaciones de aplicación de la Acción Popular cuando se presenta frente a hechos acontecidos con anterioridad a su entrada en vigencia. Por tanto, resolvió revocar las sentencias de tutela proferidas por la Sección Quinta del 4 de septiembre de 2003 y la Sección Primera del Consejo de Estado del 30 de enero de 2004 y en su lugar, conceder la tutela al derecho fundamental del debido proceso de Mauricio Cárdenas Santamaría, además dejar sin efectos exclusivamente el numeral sexto de la sentencia AP-300 proferida el 31 de mayo de 2002 por el Consejo de Estado, Sección Cuarta, al decidir sobre la acción popular, en virtud de la cual se declaró responsable solidario por el valor no recuperado de lo pagado en exceso a Mauricio Cárdenas Santamaría en su calidad de ex ministro de Transporte. En lo demás, la sentencia del Consejo de Estado, Sección Cuarta, quedó en firme.

En el caso de Fernando Londoño - Invercolsa, de manera muy similar se han presentado hechos, que posteriormente dieron al piso con la sentencia de Acción Popular, proferida en este caso por la Sala Plena del Consejo de Estado ${ }^{15}$ y con la sentencia de tutela proferida por la Sala de Conjueces de la Sección Cuarta del Consejo de Estado, en donde a consideración de la Sala de Conjueces Sección Quinta en respuesta del

\footnotetext{
${ }^{15}$ Sala Plena de lo Contencioso Administrativo. Consejero Ponente: Camilo Arciniegas Andrade. Radicación (2500023-26-00-2002-1204-01 AP) IJ
} 
recurso de apelación de la tutela, determinó "que los fallos anteriormente referenciados adolecieron inexplicablemente de un populismo extremo e injustificado, llevando a que se cometieran errores ostensibles y grotescos y por consiguiente una evidente conculcación del derecho fundamental del debido proceso, ya que era constatable la aplicación de una ley con efectos retroactivos cuando dicho efecto no resultaba ser lo consignado en la vigencia de la Ley 472 del 98 , considerando además la Sala de Conjueces Sección Quinta, "que los derechos colectivos y la moralidad pública por hechos precedentes a la vigencia de la Ley 472 del 98 , encuentran protección en los mecanismos instituidos por el ordenamiento jurídico preexistente, sin ser admisible, en un Estado Social de Derecho, aplicar normas inexistentes para la época de su consumación y, en todo caso, posteriores a ésta, menos tratándose de la responsabilidad y la imposición de condenas, por que viola el derecho constitucional fundamental del debido proceso y el principio de legalidad que implica que las situaciones, relaciones jurídicas, las conductas y sus consecuencias deben juzgarse conforme a la leyes vigentes ${ }^{16}$.

Bajo estos argumentos se decidió anular todo lo actuado hasta ese momento y conceder las pretensiones de devolver las acciones objeto del litigio, a la arrendadora Financiera Bolivariana, quien había recibido las acciones de Invercolsa, por parte de Fernando Londoño Hoyos, a través de una dación en pago.

Ésta sentencia de tutela junto con la del caso Dragacol - Ministerio de Transporte, ha dejado un impacto bastante perjudicial sobre la imagen de la acción popular, quedando en tela de juicio el desarrollo garantista que hasta hace poco había alcanzado la jurisprudencia trazada por el Consejo de Estado, cuando el contrato estatal originaba situaciones perjudiciales a los derechos colectivos, y hasta hace poco, porque la tendencia garantista, progresivamente ha venido en retroceso debido a la aplicación reciente en la jurisprudencia contenciosa administrativa, de una perspectiva metodológica que hace prevalecer un criterio de caracterización de la moral administrativa de modo inmanente, con lo cual se le despoja del carácter trascendente y de su entidad objetiva, reflejando como carácter absoluto de dicha postura, la exigencia probatoria de acreditar la mala fe y la vulneración de otros derechos colectivos para proceder a proteger la moralidad administrativa, desviando por completo el fin constitucional y legal de la prevención del daño contingente, fin que persigue la acción popular cuando se está presente ante ilegalidades y manejos reprochables evidentes, que ponen en serio peligro de ser vulnerado el derecho colectivo objeto de controversia, en este caso el de la moralidad, situación que ha conllevado a que se presenten casos donde la moralidad administrativa ha dejado de protegerse por lo exigente que resulta acreditar la mala fe del agente público en el desarrollo de la actividad contractual, como de pretender protegerla cuando el daño y la vulneración a la moralidad o al patrimonio público ya han sido consumados, y además ésta nueva tendencia jurisprudencial resulta siendo una interpretación aislada del enunciado constitucional (artículo 209), el cual al categorizar la moral administrativa como principio-derecho no lo condiciona a la conexidad con otros derechos o principios, sino que de modo directo, la constitución le otorga un sentido autónomo; además se encuentra que la exigencia probatoria de acreditar la mala fe, es ajena a la interpretación que se desprende de la Ley 472 del 98 cuando se proteger la moral administrativa, pues en ningún aparte

\footnotetext{
${ }^{16}$ Consejo De Estado. Sala de Conjueces Sección Quinta. Consejero Ponente: William Nahen Vargas. 3 de Noviembre de 2005. Exp; 11001-03-15-00-2004-00751-01.
} 
se referencia dicha exigencia, siendo ésta una creación jurisprudencial reciente que empieza a generar serios retrocesos en lo que se había ganado con la Acción Popular como instrumento ideal en la protección de la moralidad administrativva, convirtiéndola poco a poco en un eunuco adorno del sistema jurídico, perdiendo por lo consiguiente su eficacia real y quedando en un simple establecimiento formal.

\section{CONCLUSIONES}

Hasta aquí nos encontramos frente a dos retrocesos significativos sobre la Acción Popular al momento de ejercitarse frente a los contratos estatales.

El primero, se refiere a lo ocurrido en los casos referenciados de Dragacol e Invercolsa, casos que exhortan a la Justicia Administrativa a que en el desarrollo procesal de la acción popular, se de el cumplimiento de las garantías fundamentales del debido proceso, para que en las decisiones que se profieran en razón de la protección a los derechos colectivos, sean en armonía con los derechos fundamentales de los sujetos procesales o terceros vinculados en el proceso, y para que decisiones de tutela posteriores no trunquen con lo alcanzado en sentencias de acción popular que hayan logrado una protección satisfactoria de los derechos de la colectividad, como también para que no se configuren antecedentes perjudiciales en contra de la Acción popular por resultar siendo ésta, un instrumento violatorio a las garantías de los administrados.

El segundo, con relación a la reciente aplicación absoluta de la exigencia probatoria de la acreditación de la mala fe, cuando se trata de proteger la moralidad administrativa, pues menoscaba la efectividad y protección integral que debe perseguir la acción popular a la hora de defender los derechos e intereses colectivos, ya que probar la mala fe se convierte en una exigencia de difícil configuración, que en ocasiones escapa a la posibilidad del actor popular, por la complejidad de los hechos que rodearon la controversia, a razón de que cada vez son más sofisticadas las modalidades de corrupción presentes en la contratación pública, y además porque pretender proteger la moralidad administrativa cuando se demuestra la mala fe del agente, resulta en contravía de la prevención del daño contingente, que busca la acción popular cuando se está en estado de amenaza el derecho colectivo, ya que al configurarse la mala fe, la moralidad estaría en estado de vulneración, impidiéndose como consecuencia de ello, la posibilidad del juez administrativo de adoptar medidas transitorias o definitivas de protección, las cuales sólo podrían aplicarse cuando se está vulnerando y no amenazando el derecho.

Éstas situaciones demandan ser redireccionadas, bajo la dinámica de plantear observaciones y argumentos, que permitan lograr afianzar los lazos de credibilidad y legitimidad en las bondadesquesepresentanalmomentodeejercitar la acción popular frente a hechos derivados de la contratación estatal o de la manifestación de la voluntad de la administración bajo otras modalidades, cuando lesionan el interés general de la colectividad, la cual a través del ejercicio de una ciudadanía responsable viene perfilando la Acción Popular como instrumento que favorece el ejercicio participativo de la sociedad civil, ya que ha entrado a constituirse en una pieza básica para lograr dar frente a la corrupción y como elemento estratégico en el alcance de la construcción y consolidación de una administración pública en el que imperen los principios éticos. 